\title{
Prevención de la trombosis que puede ser ocasionada por la vacuna contra COVID-19
}

\section{Prevention of the thrombosis that can be caused by COVID-19 vaccine}

\author{
José L. García-Vigil * y José L. García-Álvarez²
}

${ }^{1}$ Universidad Nacional Autónoma de México, Facultad de Medicina, Departamento de Farmacología; ${ }^{2}$ Instituto Mexicano del Seguro Social, Centro Médico Nacional Siglo XXI, Hospital de Especialidades. Ciudad de México, México

La vacuna contra COVID-19 de AstraZeneca (Vaxzevria, anteriormente COVID-19 Vaccine AstraZeneca) previene la enfermedad causada por el virus SARS-CoV-2 en personas de 18 años o más. La vacuna se compone de otro virus de la familia de adenovirus que ha sido modificado para contener una proteína de SARS-CoV-2; dado que la vacuna no contiene el virus en sí, no puede causar COVID-19. ${ }^{1}$

Paulatinamente, en diferentes partes del mundo se fueron registrando casos de trombosis venosa y arterial en pacientes vacunados con el producto mencionado, en especial en la Unión Europea, donde se autorizó el uso por las agencias reguladoras nacionales, situación inusual que no se identificó en los ensayos clínicos de eficacia y seguridad. Por tal motivo, el Comité de Seguridad de la European Medicines Agency (EMA) hizo una investigación al respecto y concluyó que los coágulos sanguíneos inusuales con plaquetas bajas deben figurar como efectos secundarios muy raros de Vaxzevria. ${ }^{1}$

La EMA indica a los profesionales sanitarios y a las personas que reciben la vacuna que sean conscientes de la posibilidad de que se presenten casos, muy raros, de coágulos sanguíneos combinados con niveles bajos de plaquetas, los cuales se producen dentro de las dos semanas posteriores a la vacunación. Hasta ahora, la mayoría de los casos notificados se han identificado en mujeres menores de 60 años, sin que se hayan determinado factores de riesgo específicos. De 62 casos de trombosis de senos venosos cerebrales y 24 de trombosis venosa esplácnica notificados en la base de datos de seguridad de medicamentos de la Unión Europea (EudraVigilance) del 22 de marzo de 2021, 18 fueron mortales.

Ante esa información y con las evidencias disponibles, a reserva de tener resultados de estudios de farmacoeconomía como costo-beneficio, costo-efectividad y calidad de vida, hasta el momento los beneficios superan los riesgos, por lo que es recomendable continuar con los planes de vacunación en los diferentes países donde se están implementando, incluido México. ${ }^{2}$

Por tal motivo, se justifica la profilaxis con el uso de medicamentos antitrombóticos (antiplaquetarios y anticoagulantes) ya probados tanto en prevención primaria como secundaria, como $100 \mathrm{mg}$ diarios por vía oral (d/v.o.) de ácido acetilsalicílico (Aspirina), $75 \mathrm{mg}$ d/v.o. de dipiridamol, $2.5 \mathrm{mg} \mathrm{d} / \mathrm{v} .0$. de apixabán o $2.5 \mathrm{mg} \mathrm{d} / \mathrm{v} .0$. de rivaroxabán, administrados una semana antes de la fecha de vacunación y dos semanas posteriores. De ser necesaria por factores de riesgo preexistentes de hipercoagulabilidad y bajo prescripción médica, esta profilaxis podría continuar a largo plazo.

\section{Bibliografía}

1. European Medicine Agency [Internet]. Países Bajos: AstraZeneca's COVID-19 vaccine: EMA finds possible link to very rare cases of unusual blood clots with low blood platelets; 2021.

2. WHO [Internet]. Ginebra, Suiza: COVID-19: AstraZeneca vaccine benefits still 'largely positive'; 2021 Apr 6. 